\title{
An empirical study of Urban and Rural Ecological Economic Development based on Spatial Econometric Model
}

\author{
Ruan Mingyang \\ Kunming College, Kunming, 650214, China \\ Xexi123@163.com
}

Keywords: Spatial econometrics, Ecological economy, Numerical calculation, Three-dimensional curve, Velocity contour, ArcGIS.

\begin{abstract}
Ecological economic regional development is mainly affected by the number of high-tech enterprises, new low carbon materials research, ecological environment problems and many other factors, the influence of data respectively shows obvious spatial distribution characteristics. In order to study the development of urban and rural regional ecological economy and combined with the economic development and ecological spatial data regions, the use of ArcGIS software makes an empirical study on the development of the urban and rural ecological economy. Through numerical calculation, we can get the three-dimensional space curve factors influencing the development of ecological economy and draw the development nephogram of division of urban and rural areas ecological economy, which provide a theoretical basis for the research on urban and rural ecological economy.
\end{abstract}

\section{Introduction}

In the spatial econometric estimation process of urban and rural ecological economy, we need to use large amounts of rich three-dimensional spatial characteristics data and some network digital information [1,2]. In treatment selection examples, GIS is an important factor of explicit digital information. GIS search capability should not be underestimated, it can find high-tech enterprises, low carbon new material and development enterprises research and various public facilities in region, such as supermarkets, medical establishments and so on, and it can also be used for further evaluation on the ecological problems in region, in which the main process is shown in Figure 1.

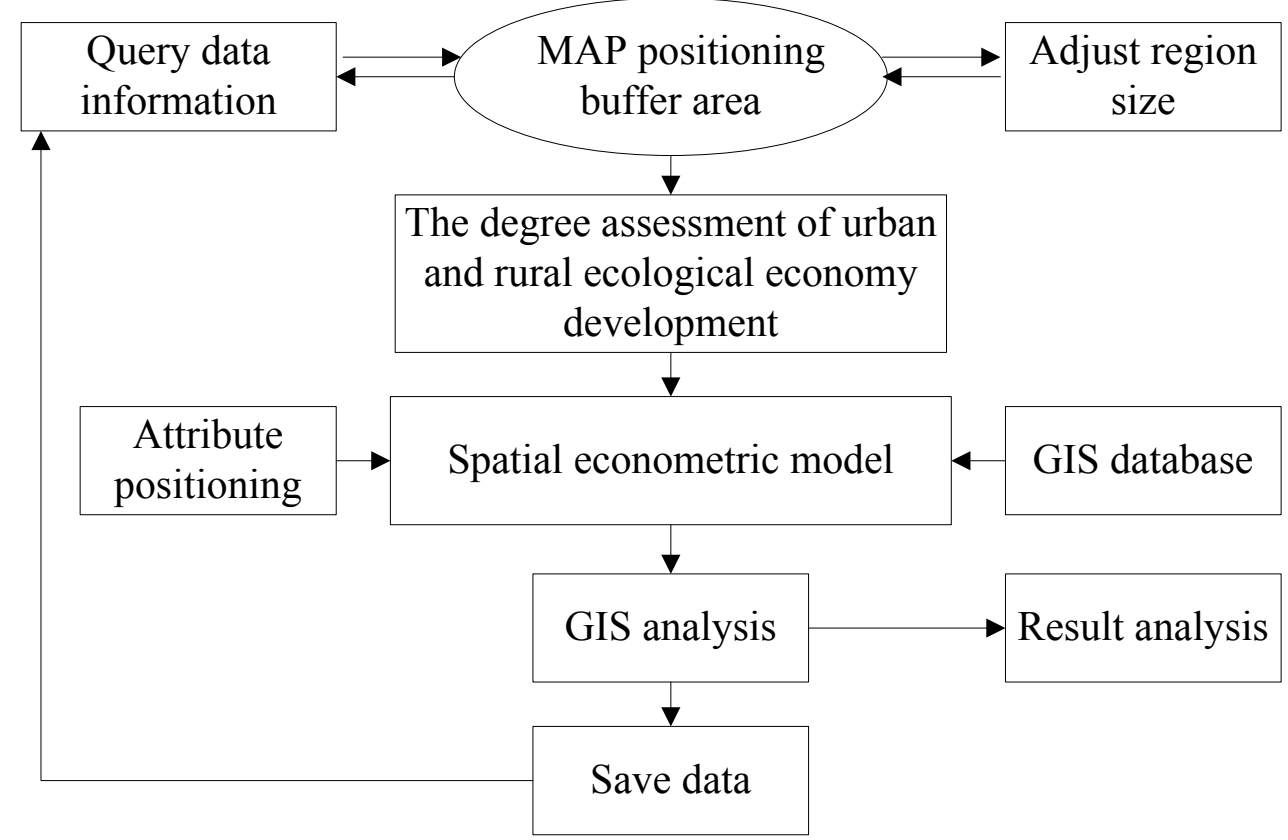

Fig. 1 Schematic diagram of GIS spatial econometric

Figure 1 shows the schematic diagram of GIS spatial econometric. Firstly, we extract the regional eco economic development data, we go through GIS assisted to search the accurate position of these 
regional, but also set up a central point in this position, at the same time taking the evaluation standards as a basis to adjust regional scope [3]. With GIS search and analysis capabilities, we find useful information and use ecological evaluation parameters, to carry on numerical calculation in AcrGIS software. Through the computation, we can obtain various factors on the $3 \mathrm{D}$ curve and cloud distribution of ecological economic development.

\section{Urban and Rural Ecological Economic Development Spatial Econometric Mathematical Model}

For the spatial data information of low carbon, new materials research and development, science and technology content in the ecological economic regional development, we want to achieve spatial data statistical visualization, we requires each evaluation region to carry on space processing [4,5]. Hypothesis that in $\left[z_{i}, z_{i+1}\right]$ evaluation interval, the establishment of GIS space generalized matrix $y_{1}, y_{2}, y_{3}, y_{4}$ and $x_{1}, x_{2}, x_{3}, x_{4}$, in which space generalized matrix of ecological economic development can be written as:

$$
X^{T}=\left[\begin{array}{llllllll}
x_{1} & x_{2} & x_{3} & x_{4} & y_{1} & y_{2} & y_{3} & y_{4}
\end{array}\right] .
$$

The form of space vector is shown in formula (2).

$$
x(m, n)=\alpha a .
$$

Where

$$
\begin{aligned}
& \alpha=\left[\begin{array}{ll}
\alpha & 0 \\
0 & \alpha
\end{array}\right] \\
& a^{T}=\left[\begin{array}{lllllllll}
a_{1} & a_{2} & a_{3} & a_{4} & b_{1} & b_{2} & b_{3} & b_{4}
\end{array}\right] .
\end{aligned}
$$

For each block evaluation of urban and rural economy, we can use the following expressions.

$\bar{X}=X a$.

We can get the generalized coordinates $a$ that is

$$
a=X^{-1} \bar{X} .
$$

Among them,

$$
X^{-1}=\left[\begin{array}{cc}
\bar{X}^{-1} & 0 \\
0 & \bar{X}^{-1}
\end{array}\right] \text {. }
$$

So we can establish the spatial econometric model of urban and rural eco economic regional evaluation that is

$$
K(m, n)=\alpha X^{-1} \text {. }
$$

Therefore, the different urban and rural areas can use different economy development mathematics to evaluate development speed, and we can obtain the development spatial econometric nephogram of ecological economy [6]. Urban and rural eco economic regional evaluation model can use data interface programming and software to establish the data relationship, in which the main procedures are as follows:

using ESRI.ArcGIS.Carto;

using ESRI.ArcGIS.Catalog;

using ESRI.ArcGIS.CatalogUI;

using ESRI.ArcGIS.Controls;

using ESRI.ArcGIS.Display;

using ESRI.ArcGIS.esriSystem;

using ESRI.ArcGIS.Geodatabase; 
using ESRI.ArcGIS.Geometry;

using ESRI.ArcGIS.Output;

using ESRI.ArcGIS.SystemUI;

\section{Urban and Rural Ecological Economic Spatial Measurement Numerical Calculation}

In order to verify the effectiveness and reliability of GIS spatial statistical mathematical model and algorithm designed in second part, this paper uses the AcrGIS software on the city eco economic to carry on spatial econometric evaluation, and carries out numerical calculation for the development speed of the cloud [7,8]. The ArcGIS software platform is shown in Figure 2.

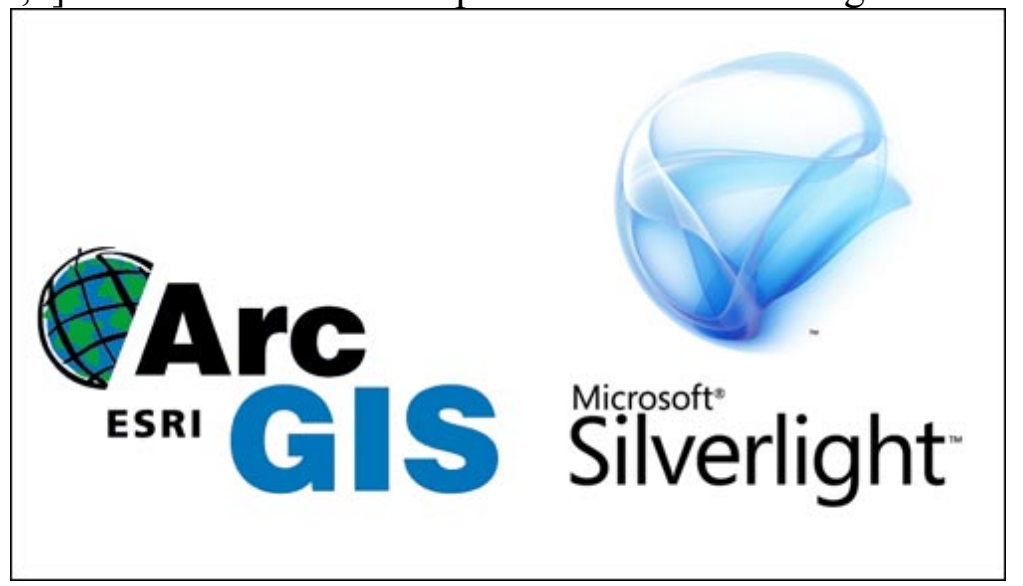

Fig. 2 Schematic diagram of the ArcGIS software platform

Figure 2 shows the schematic diagram of the ArcGIS software platform, the product line provides a scalable and comprehensive GIS platform for the user [9]. The ArcObjects contains a large number of programmable components, which covers a wide range from the fine-grained objects to coarse-grained object, these objects are integrated a comprehensive GIS function for developers.

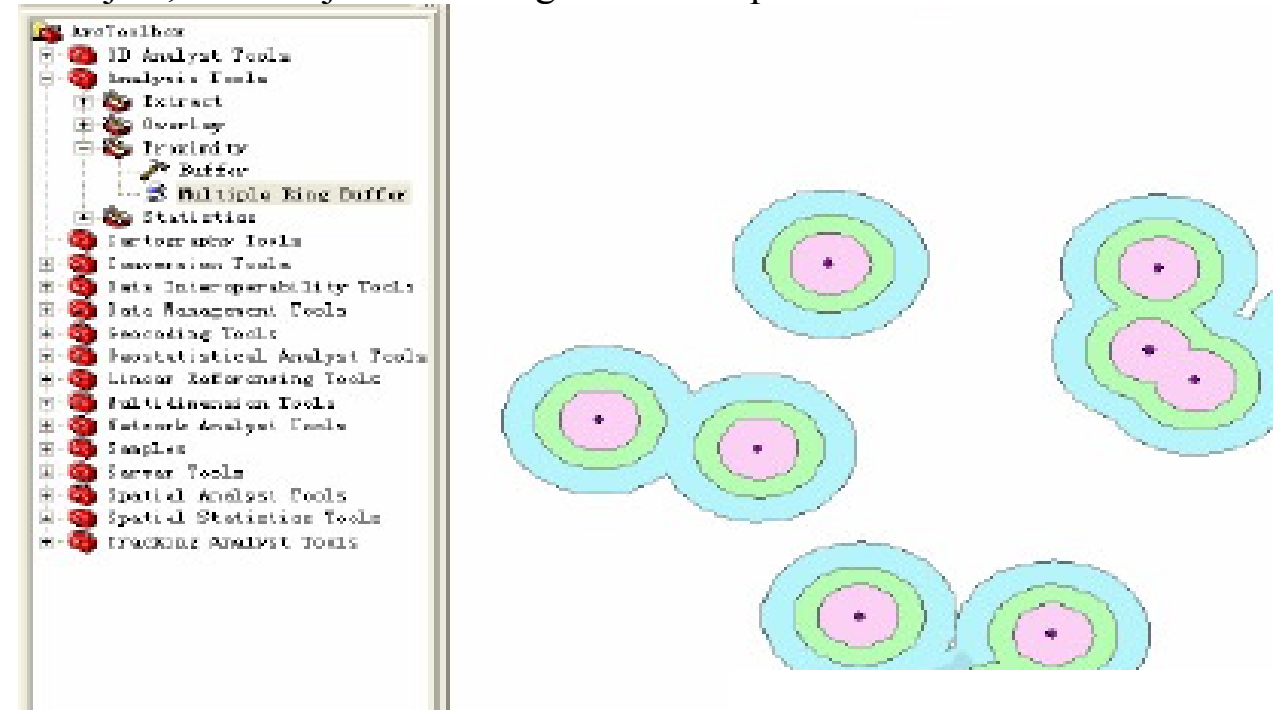

Fig.3 GIS designated regional assessment

Figure 3 shows the schematic diagram of regional assessment designated by using the GIS urban and rural ecological economy software. From the chart, urban and rural will be divided into different blocks, to assess the overall development of economy using eco economic regional development low carbon, new material R \& D and of science and technology content in three directions, in which the assessment curve is shown in Figure4. 


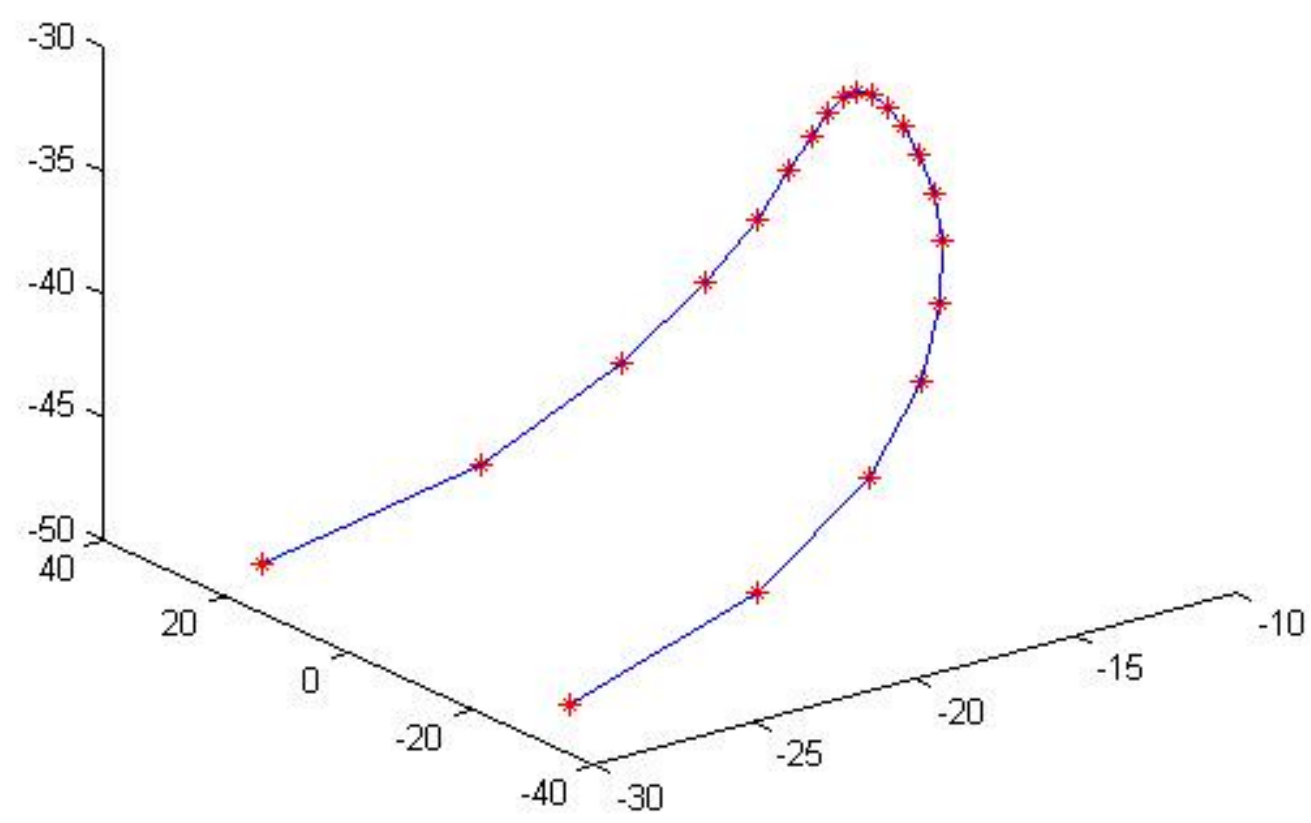

Fig.4 The three-dimensional space distribution of key ecological economic development

Figure 4 shows the 3D simulation curves calculated by using GIS software, including the low carbon, new materials research and development and science and technology content parameters of eco economic regional development, these three parameters will be added to each block assessment model, so we can get the speed development cloud of urban and rural eco economic.

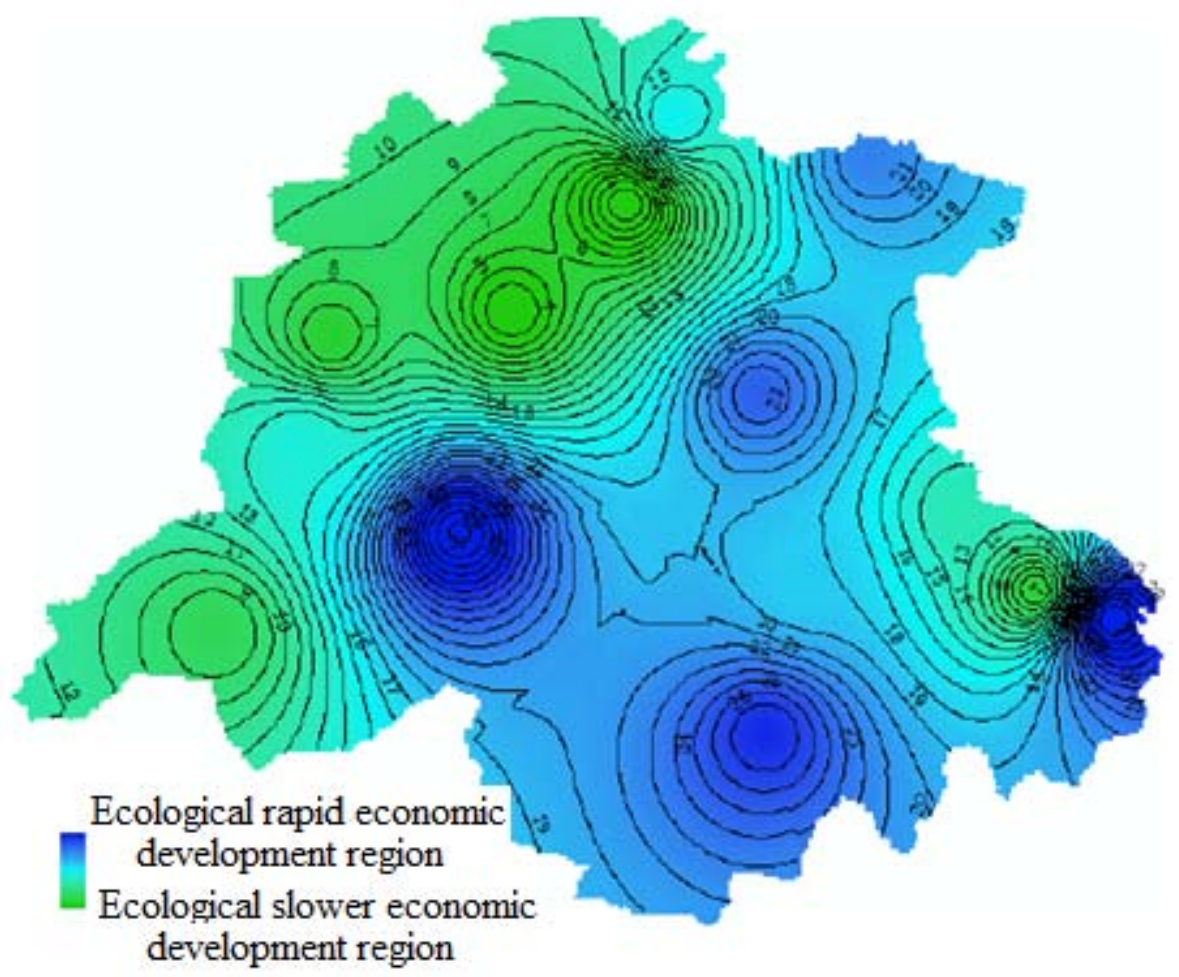

Fig.5 Urban and rural economic development speed nephogram

Figure 5 shows the urban and rural economic development speed nephogram that is drown by using GIS spatial econometric statistical software. From the chart, red and green respectively represent better ecological economic development and slower region [10]. Through the cloud, we can effectively determine the difference of urban and rural regional economy development, to promote the development of ecological economy. 


\section{Summary}

(1) According to the space distribution characteristics of data and the combination of generalized matrix theory, we establish the spatial statistical vector model of eco economic regionalization evaluation, and is imported model by using ArcGIS data interface, to realize the spatial statistics regional methods of ecological economic development evaluation.

(2) In order to verify the reliability of the model, we make an empirical study on the development of urban and rural ecological economy and get three dimensional spatial distribution curves and economic development speed cloud of affecting ecological economic development factors, which provide data reference for the development of urban and rural regional economy. But the universal applicability of the algorithm remains to be further studied, for example it is applied to real estate development assessment, environmental engineering assessment system and so on, which will have a more broad application prospects.

\section{References}

[1] Z.P. Ren. The potential and actual effect of energy prices fluctuations on our country price level. Economic research, 2012(8): 67-68.

[2] X. Li, Y.Y. Mu, L.L. Zheng. The asymmetric effect of grain price fluctuation on the price level--An Empirical Analysis Based on STR model. Statistic and information forum, 2012(7): 126-127.

[3] X.M. Fang, A.J. Sun, Y.F. Cao. Research on financial support and economic growth based on spatial model from China provinces1998 2008 evidence. Financial research, 2010(10): 78-79.

[4] X.Y. Qian, C. Wei, W. Li. The influence of human capital on our country regional innovation and economic growth: the empirical study of spatial econometric. Quantitative technical economics, 2010(4): 89-90.

[5] Y.M. Zhang, K. Li. Study on the innovation spatial distribution and spatial correlation in China -the spatial econometric analysis based on the1996-2005 provincial patent statistical data. China soft science, 2011 (11): 156-157.

[6] X.S. Wang, S.X. Xie. International agricultural products prices affect our country agricultural products price. Economic research, 2012(3): 35-36.

[7] Q.Q. Liu. Resident income, pork price and money supply based on 2001-2010 empirical data. Agricultural technology economics, 2012(1): 67-68.

[8] Z.Z. Han, K. An, L. Gui. Empirical study of regional economic coordination development in China. Statistical research, 2012(1): 89-90.

[9] C. Wang. Capital accumulation, tax interaction and vertical tax competition. Economics, 2012(1): 45-46.

[10] J.W. Li. The impact factors and its contribution assessment of our country consumer prices rose. Dynamic economics, 2011(8):112-113. 